\title{
Estimation of Distribution Transformer Losses in Feeder Circuit
}

\author{
V. A. Kulkarni and P. K Katti
}

\begin{abstract}
Losses of distribution transformers (DT) in a distribution system (DS) depend on mainly load. Actual measurement of these losses is in substation (SS) feeder circuit is not easy due to many inconveniences like difficulty in installation of meters, unfavourable locations and conditions. But as the DT losses are sizeable they need to be considered for overall loss calculations. In this paper, an approach is developed to estimate the DT losses in a feeder circuit. Losses of individual DTs are calculated and summed up to give the losses due to DT circuit. A sample case of a large power system is considered. The losses are calculated by the said approach. The overall DT circuit losses are $8.57 \%$ of the total import.
\end{abstract}

Index Terms-Feeder circuit, Loss calculation, Loss factor, Transformer losses.

\section{INTRODUCTION}

Energy losses of a power system are calculated by two methods:

i. Actual readings and ii. Analytical calculations.

A large DS comprises of feeder lines, DTs and end users. Generally the loss measurement is through a simple empirical formula given by Losses equal to difference between input and output in units ( $\mathrm{kWh})$. However, if it is required to estimate the losses of individual sections like only feeder or transformer circuits, it is practically difficult. For this purpose, it is necessary to install the meters in the individual circuits. Because of topography, vast area and inconveniences in installing and noting down, the actual readings method is practically difficult.

The analytical method may be approximate. Sometimes the results may differ too much with that of the practical values giving rise to big gap in the two estimations. Therefore, the best method is to combine these two methods and estimate the best possible losses near to accuracy[8].

In this paper, a method that includes the load variability and corresponding actual readings are considered. The period is one month.

The two methods are used to estimate the losses in the transformer circuit in a feeder and a new approach is presented.

The organization of this paper is as follows:

Firstly, the power system SS, its components like feeder and DT are discussed. Various losses in DTs are discussed.

Manuscript received March 15, 2011; revised September 30, 2011

V. A. Kulkarni Working as faculty member in Dept. of Electrical Engineering at Padmashree Dr. D.Y. Patil Institute of Engg and technology, Pune, India (email: vjykulkarni58@yahoo.com).

P. K Katti Working as Head of Dept. of Electrical Engineering at Dr. Babasaheb Ambedkar. Technological University, Lonere, India. (email: pk_katti2003@yahoo.com)
Next, approach for estimating the losses of DT circuit is presented using actual readings available and analytical methods.

A large power system is considered as sample case study. The load profile, based on the consumer's data, is described. The approach is implemented for the loss calculations. Results and conclusions are drawn on the basis of calculations.

\section{SubStation (SS) FeEder Circuit}

Energy is supplied from the substation to the end users (consumers) by feeder circuit. It can be divided into two parts as :

i. HT feeder line which a conductor overhead or underground (ACSR or HT cable) and

ii. Ttransformer (DTs).

Fig.1 shows a typical feeder circuit indicating the deployment of DTs in branches and sub branches.

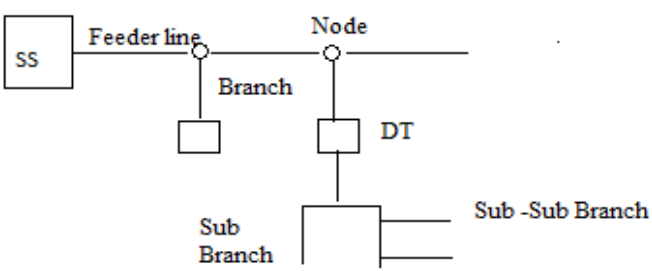

Fig.1. Typical Feeder Circuit

\section{A. Distribution Transformers(DT) Losses}

Since transformers are inductive in nature they consume the power with lagging power factor. But the key input for estimating distribution transformer energy loss is the transformer load that determines the power factor and energy consumed. The distribution transformer rated capacity does not reflect their actual consumption. Therefore, there is no measured load records for distribution transformers when the feeder is supplying the energy. The loss due to DT is of significance as it contributes to some percentage of total input units. Attempts may be made to minimize these losses.

Losses are broadly classified as [1]:

i. No load losses $\left(\mathrm{W}_{\mathrm{i}}\right)$ : Taking place in iron /core part comprising of hysteresis Losses and eddy current losses in the Core considered to be constant irrespective of load.

ii. Winding losses or load loss $\left(\mathrm{W}_{\mathrm{wdg}}\right)$ : Taking place in the winding part. As a function of load current, can be divided into $\left(I^{2} R\right)$ loss and stray losses. The stray losses are caused by eddy-currents that produce stray electromagnetic flux in the windings, core, core clamps, magnetic shield and other parts of the transformer 
iii. Other losses $\left(\mathrm{W}_{\text {other }}\right)$ : dielectric loss ( due to electrostatic reversal in insulation and circulating currents), load unbalance, oil leakage, loss of life, lack of maintenance, improper up keep of distribution boxes, and joints loose connections. Generally the value is less than $1 \%$ of total energy input to the system.

The most important losses are $\mathrm{W}_{\mathrm{i}}$ and $\mathrm{W}_{\mathrm{wdg}}$. The other losses are described mainly to give a complete picture on losses.

\section{B. Loss Calculation Approach}

$\mathrm{T}=$ Period of consideration (day/month/year)

$\mathrm{kVA}_{\mathrm{av}}=$ Average of recorded $\mathrm{kVA}$ from load curve $=\sum_{\mathrm{i}=1}^{\mathrm{T}}$ kVA(i) / T

Load factor $\left(\mathrm{L}_{\mathrm{d}}\right)$ :It is the ratio of the average $\mathrm{kVA}$ consumed during a designated period, to the maximum demand (MDkVA) occurring in that same period. A system load factor measures the degree of utilisation of the power supply system. By increasing the system load factor, the need to provide larger building transformer capacity may be avoided and the construction of new generating and transmission plant may be delayed or the magnitude of the increase reduced. It is given by [7]

$$
\text { Load factor }=\mathrm{L}_{\mathrm{d}} \mathrm{F}=\left(\mathrm{kVA}_{\mathrm{av}}\right) /(\mathrm{MDkVA})
$$

Loss factor $\left(\mathrm{L}_{\mathrm{s}} \mathrm{F}_{\mathrm{actr}}\right)$ : It describes the average electrical energy losses for electricity transmitted during T. Ideally, to calculate the load losses it would be necessary to integrate the squares of all momentary ratios of actual load to the rated load. This is practically difficult. Therefore, summation of energy consumed in transformers is developed given by[2]-[5] :

$$
\text { Loss factor }=\mathrm{L}_{\mathrm{s}} \mathrm{F}_{\mathrm{actr}}=\mathrm{L}_{\mathrm{d}} \mathrm{F}^{2}+(0.273)\left(\mathrm{L}_{\mathrm{d}} \mathrm{F}-\mathrm{K}\right)^{2}
$$

where $\mathrm{K}=\left(\mathrm{kVA}_{\text {min })} /\left(\mathrm{kVA}_{\text {max }}\right)\right.$ (as per load curve $)$

Now, $\mathrm{W}_{\mathrm{wdg}}=\mathrm{W}_{\mathrm{c}}[(\mathrm{MD} \mathrm{kVA}) /(\text { Tr kVA total })]^{2}\left(\mathrm{~L}_{\mathrm{s}} \mathrm{F}_{\mathrm{actr}}\right)$ where $\mathrm{Wc}=$ Full load Copper loss

$\mathrm{W}_{\mathrm{i}}$ and $\mathrm{W}_{\mathrm{c}}$ can be obtained from the standard losses table available.

Tr $\mathrm{kVA}_{\text {total }}=$ Total ratings of all transformer $\mathrm{kVA}$

Transformer energy losses are given by $\mathrm{TR}_{\text {Enloss }}=\left(\mathrm{W}_{\mathrm{i}}+\right.$ $\left.\mathrm{W}_{\text {wdg }}+\mathrm{W}_{\text {other }}\right) \mathrm{T}$

Total Losses for all distribution transformers can then be calculated by summing the losses for individual transformer as below:

Total Transformer energy losses $=\sum_{i=1}^{n} T_{\text {Enloss }}(i)$

\section{SAMPLE CASE STUDY}

A large scale power system is considered in Pune, India. The Substation (SS) is located in dense industrial area comprising Small Scale Industries (SSIs), medium and large industries. Working voltage of SS is $220 \mathrm{kV} / 22 \mathrm{kV}$ having 44 feeders. $90 \%$ of the power is supplied to industries. Feeder No12 is selected for sample study. The period of study was one month (for 30 days) in May 2010. The feeder is drawn through distance of $15 \mathrm{~km}$. Figure 2 shows the load curve profile the feeder circuit .

Maximum consumption is 68541 units on sixth day, minimum is 58000 units on fifth day and average is 62533.3 units. And maximum is $38000 \mathrm{kVA}$ on twentieth day, minimum is $13876 \mathrm{kVA}$ third day and average is 20562.8 kVA.

Standard transformer losses are shown in Table I.

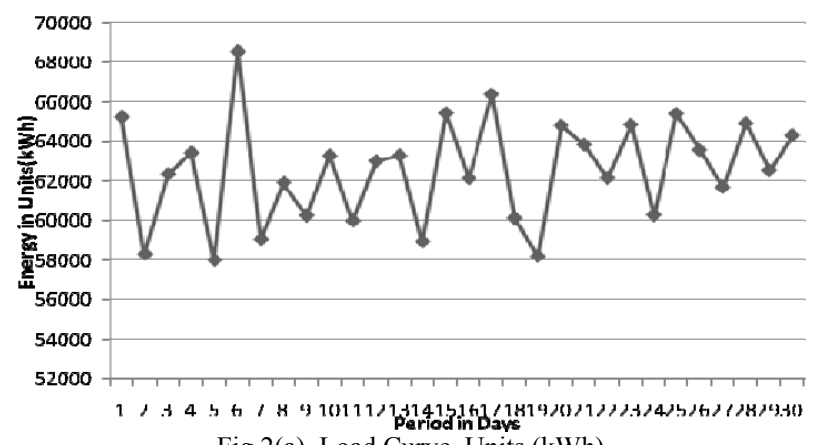

Fig.2(a). Load Curve Units (kWh)

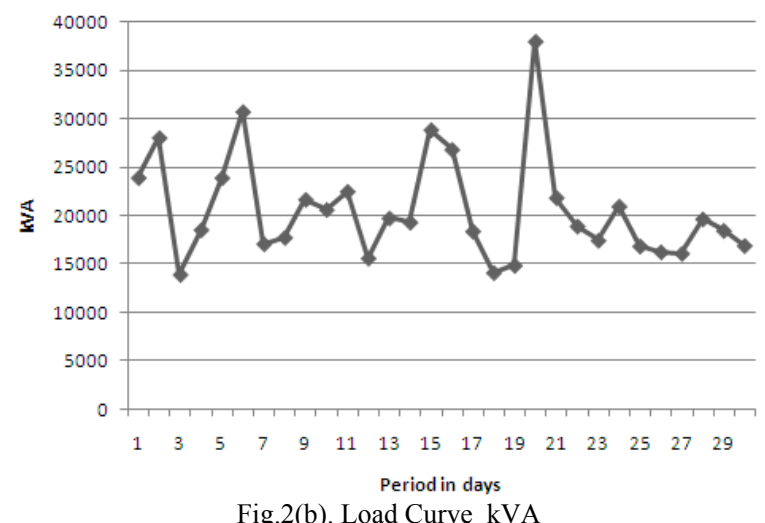

TABLE I: STANDARD TRANSFORMER LOSSES

\begin{tabular}{|l|l|l|l|}
\hline Sl. No. & Transformer rating $k V A$ & $\mathrm{~W}_{\mathrm{i}}(\mathrm{W})$ & $\mathrm{W}_{c}(\mathrm{~W})$ \\
\hline 1. & 100 & 350 & 2500 \\
\hline 2. & 200 & 570 & 3300 \\
\hline 3. & 315 & 800 & 4600 \\
\hline 4. & 500 & 1100 & 6500 \\
\hline 5. & 1000 & 1800 & 11000 \\
\hline 6. & 2000 & 3000 & 20000 \\
\hline
\end{tabular}

All are oil immersed transformers. Overall transformer capacity is $44205 \mathrm{kVA}$. It is clear from the tableI that 2000 $\mathrm{kVA}$ transformers have the major share of about half of the total capacity. These transformers are mainly used for SSIs which are LT consumers. Table II shows the details of the transformers in the feeder circuit and their share in the overall transformer capacity.

TABLE II: DATAILS OF TRANFORMERS USED

\begin{tabular}{|l|l|l|l|l|}
\hline $\begin{array}{l}\text { Sl. } \\
\text { No }\end{array}$ & $\begin{array}{l}\text { Transformer } \\
\text { rating kVA }\end{array}$ & Qty & $\begin{array}{l}\text { Total } \\
\text { kVA }\end{array}$ & $\begin{array}{l}\text { Percentage (\%) of } \\
\text { Overall Total capacity }\end{array}$ \\
\hline 1. & 100 & 15 & 1500 & 3.39 \\
\hline 2. & 200 & 10 & 2000 & 4.52 \\
\hline 3. & 315 & 07 & 2205 & 4.99 \\
\hline 4. & 500 & 15 & 7500 & 16.97 \\
\hline 5. & 1000 & 11 & 11000 & 24.88 \\
\hline 6. & 2000 & 10 & 20000 & 45.24 \\
\hline $\begin{array}{l}\text { Total Overall } \\
\text { Tr kVA total }\end{array}$ & $\mathbf{6 8}$ & $\mathbf{4 4 2 0 5 k V A}$ & \\
\hline
\end{tabular}

Out of 68 DTs, $50(73.5 \%)$ are installed before 20 years. The total transformer capacity is loaded to $87 \%$ (38000 MD $\mathrm{kVA}$ of feeder). The power system is very large and the available manpower is proportionately less. Hence routine maintenance of transformers is carried out once in three years. Therefore, transformer losses are expected to be more. 
All the DTs are essentially located near the load centers. The cables drawn to the loads are not more than $25 \mathrm{mts}$., reducing the losses in the cables.

Table III indicates the calculated values of various factors

TABLE III: FACTORS USED FOR LOSS CALCULATIONS

\begin{tabular}{|c|c|}
\hline $\mathrm{L}_{\mathrm{d}} \mathrm{F}$ & 0.539 \\
\hline $\mathrm{K}$ & 0.365 \\
\hline $\mathrm{L}_{\mathrm{s}} \mathrm{F}_{\text {actr }}$ & 0.298 \\
\hline
\end{tabular}

Transformers in electricity distribution companies have low loadings for many reasons. DTs are protected against short circuit, but not against overload or excessive temperature. The anticipated high variability of load and the need to reserve capacity to provide resilience against failure of other equipment are some of the reasons[9].

\section{RESUltS}

As per the load curve data, total consumption (SS import) is 1876000 units, $616884 \mathrm{kVA}$ per month.

Although transformer capacity is loaded to recorded value up to $38000 \mathrm{MD} \mathrm{kVA}$ collectively but considering the low values of the factors, it can be noted that in terms of loading, the utility of transformers is less.

Table IV presents the losses of DTs grouped as per the ratings.

TABLE IV(a): DAILY ENERGY LOSS OF TOTAL TRANSFORMER CIRCUIT

\begin{tabular}{|c|c|c|c|c|c|c|}
\hline \multirow[b]{2}{*}{$\begin{array}{l}\text { Sl. } \\
\text { No. }\end{array}$} & \multirow{2}{*}{$\begin{array}{c}\text { Tranformer } \\
\text { Type } \\
\text { (kVA) }\end{array}$} & \multirow[b]{2}{*}{ Qty } & \multicolumn{3}{|c|}{ Energy Losses in Units(kWh) } & \multirow{2}{*}{$\begin{array}{l}\text { Total } \\
\text { Units } \\
(\mathrm{kWh})\end{array}$} \\
\hline & & & $\mathrm{W}_{\mathrm{i}}$ & $\mathrm{W}_{\text {wdg }}$ & $\begin{array}{c}\text { Other losses } \\
\mathrm{W}_{\text {other }}\end{array}$ & \\
\hline 1. & 100 & 15 & 108 & 147 & 27 & 282 \\
\hline 2. & 200 & 10 & 112.8 & 158.4 & 41 & 312.2 \\
\hline 3. & 315 & 07 & 103.6 & 155.2 & 34 & 292.8 \\
\hline 4. & 500 & 15 & 324 & 459.3 & 78 & 861.3 \\
\hline 5. & 1000 & 11 & 475.2 & 871.2 & 146 & 1492.4 \\
\hline 6. & 2000 & 10 & 720 & 1056 & 237 & 2013 \\
\hline \multicolumn{3}{|c|}{ Total } & 1843.6 & 2847.1 & 563 & $\mathbf{5 2 5 3 . 7}$ \\
\hline
\end{tabular}

TABLE IV(b): MONTHLY ENERGY LOSS OF TOTAL TRANSFORMER CirCUIT

\begin{tabular}{|c|c|c|c|c|c|c|}
\hline \multirow{2}{*}{$\begin{array}{l}\text { Sl. } \\
\text { No. }\end{array}$} & \multirow{2}{*}{$\begin{array}{c}\text { Tranformer } \\
\text { Type } \\
\text { (kVA) }\end{array}$} & \multirow[b]{2}{*}{ Qty } & \multicolumn{3}{|c|}{ Energy Losses in Units(kWh) } & \multirow{2}{*}{$\begin{array}{c}\text { Total } \\
\text { Units } \\
(\mathrm{kWh})\end{array}$} \\
\hline & & & $\mathrm{W}_{\mathrm{i}}$ & $\mathrm{W}_{\text {wdg }}$ & $\begin{array}{c}\text { Other (Oil, } \\
\text { Joints, Life ) }\end{array}$ & \\
\hline 1. & 100 & 15 & 3240 & 4410 & 810 & 8460 \\
\hline 2. & 200 & 10 & 3384 & 4752 & 1230 & 9266 \\
\hline 3. & 315 & 07 & 3108 & 4656 & 1020 & 7864 \\
\hline 4. & 500 & 15 & 9720 & 13779 & 2340 & 25839 \\
\hline 5. & 1000 & 11 & 14256 & 26136 & 4380 & 44772 \\
\hline 6. & 2000 & 10 & 21600 & 31680 & 7110 & 60390 \\
\hline \multicolumn{3}{|c|}{ Total } & 55308 & 76251 & 15870 & 156591 \\
\hline
\end{tabular}

The table $\mathrm{V}$ shows losses of each group as percentage of total import units in the feeder.

TABLE V: RATING WiSE TRANSFORMER LOSSES FOR ONE MONTH
\begin{tabular}{|l|l|c|}
\hline $\begin{array}{l}\text { Sl. } \\
\text { No. }\end{array}$ & $\begin{array}{l}\text { Tranformer Type } \\
(\mathrm{kVA})\end{array}$ & $\begin{array}{l}\text { Percentage(\%) Of Total } \\
\text { input (import) Units(kWh) }\end{array}$ \\
\hline 1. & 100 & 0.45 \\
\hline 2. & 200 & 0.5 \\
\hline 3. & 315 & 0.63 \\
\hline 4. & 500 & 1.38 \\
\hline 5. & 1000 & 2.39 \\
\hline 6. & 2000 & 3.22 \\
\hline Total & $\sum$ & $\mathbf{8 . 5 7 \%}$ \\
\hline
\end{tabular}

Fig. 3 shows the losses of the transformers grouped according to the ratings.

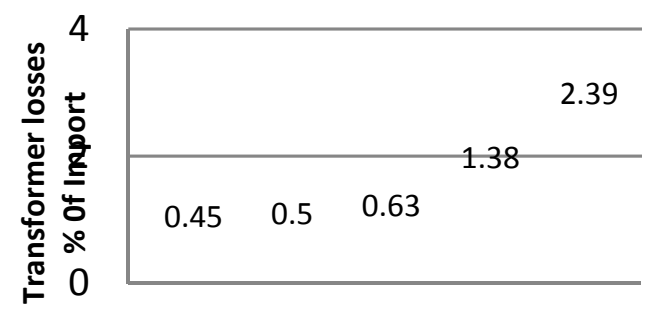

Fig.3. Transformer losses as percentage of total import

\section{CONCLUSIONS}

The method used in this paper makes use of the past data of the feeder circuit. By calculating the factors, the losses can be easily calculated.

Total losses due transformers in the feeder circuit is $8.57 \%$ of the total input to the substation.

This quantity of loss is seemingly little high as compared to normal losses of 5 to $6 \%$ in a feeder circuit. More losses in present case can be attributed to life, poor maintenance and environmental aspects. If maintenance work is done with planning, at least 5000units $(0.3 \%)$ can be saved. It can be noted that the losses are more for high rated transformer groups. This is because they are connected to bulk LT consumers. The network is large and covers many versatile types of machinery. Hence the losses are expected to be more. Transformers of low ratings are connected to HT consumers. Compared to LT consumers, HT consumers are less in number and are cautious about energy saving activities. Energy Conservation in HT sector is comparatively wide and easy.

\section{REFERENCES}

[1] Guidelines on Energy Efficiency of Electrical Installations Electrical and Mechanical Services, Department of Energy, Government of Hong Kong Special Administrative Region, 1999

[2] Adriano Galindo Leal, José Antonio Jardini, Luiz Carlos Magrini, and Se Un Ahn "Distribution Transformer Losses Evaluation A New Analytical Methodology and Artificial Neural Network Approach", IEEE Tr. On Power Systems, vol. 24, no. 2, May 2009705 pp705.

[3] J. A. Jardini, C. M. V. Tahan, M. R. Gouvea, S. U. Ahn, and F. M. Figueiredo, "Daily load profiles for residential, commercial and Industrial low voltage consumers," IEEE Trans. Power Del., vol. 15, no. 1, pp. 375-380, Jan. 2000.

[4] Selecting Energy Efficient Distribution Transformers - A Guide for Achieving Least-Cost Solutions -,Polish Copper Promotion Centre and European Copper Institute , June 2008

[5] Alejandro Navarro, and H Rudnik "Large scale Distribution Part-I: simultaneous Network and transformer Optimization and part -II", IEEE Tr. on Power Systems, Vol24, No2, pp744/752.

[6] Juan, O Galvan,Pavlos, Georgilakis and R O Vadez, 'A review of transformer losses' Electric power components and systems ,v33, No.10, Oct2005 pp1046

[7] Dr M K Khedkar,G M Dhole and V S Ingle, "Optimal load transfer: strategy for loss reduction of distribution network" IEI Journal,-El, V84, Dec2003.

[8] V A Kulkarni and Dr. P K Katti, "Efficient utilization of energy in industry- energy management perspective "IEEE International Con. on Power Technol. POWERCON2010 OCT 2010, China.

[9] V A Kulkarni and Dr. P K Katti,"Assessment of Energy Efficiency in SSI cluster by implementing energy efficient systems" International Conference on Advances in Renewable Energy ICARE2010, Bhopal, India, June2010, pp259. 


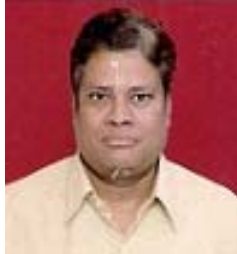

Vijaykumar Annaji Kulkarni received his degree in Electrical Engineering (B.E.) from University Vishveshwaraiah College of Engineering, Bangalore, India in 1982 and Master of Engineering (M.E) in Electrical Power Systems from Govt. College of Engg. Pune, India in 1994. He is working as faculty member in Padmashree Dr. D.Y.Patil Institute of Engg.\& Tech. Pune, India. He is member of IEEE and IE(India).

He has published many technical research papers at national and international level. His areas of interest are energy conservation , management, DSM and application of energy technology for rural areas. $\mathrm{He}$ is pusuing $\mathrm{Ph} \mathrm{D}$ under the guidance of Dr. P K Katti

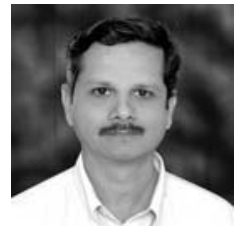

Pradeep. K. Katti was born in 1961. He graduated from Mysore University's degree in Electrical Engineering (Power) from BIET-Davanagere in 1985. He obtained M.E (Control System) from Govt. College of Engineering of Pune University in 1991. $\mathrm{He}$ obtained $\mathrm{Ph}$. D in Energy system from VNITNagpur - India in2007.

He has a wide teaching experience, and presently working with Dr. Babasaheb Ambedkar Technological University, Lonere, India as professor and Head in the Dept. of Electrical Engineering. He has guided projects at U.G. \& P.G. and $\mathrm{PhD}$ research level. He has several Publications to his credit at international and national level through conferences, journal, magazines etc. 